\title{
Use of double-balloon catheter in the management of epistaxis: A boon for the periphery
}

\author{
Bista $\mathbf{M}^{1}$, Baranwal $C^{2}$, Maharjan $\mathbf{M}^{3}$, Kafle $\mathbf{P}^{1}$, Shrestha $\mathrm{S}^{1}$, Toran $\mathrm{KC}^{4}$
}

${ }^{1}$ Assistant Professor, ${ }^{2}$ House Officer, ${ }^{3}$ Lecturer, ${ }^{4}$ Associate Professor and HoD, Department of Otorhino-laryngology and Head and Neck Surgery, Kathmandu Medical College, Sinamangal, Nepal.

\begin{abstract}
Background: Epistaxis is one of the most commonly encountered emergencies in ENT practise. It has been reported that almost $60 \%$ of general population experience epistaxis of small or large quantity in his /her lifetime ${ }^{1}$.

Objective: The objective of this study was to compare the outcome of double ballon catheter to normal packing method for epistaxis.

Materials and methods: An interventional study of 30 patients admitted in Kathmandu Medical College, Sinamangal, Kathmandu, Nepal from mid April 2008 to mid April 2009 with bleeding from the nose were taken into study. These patients were analysed on the basis of duration of hospital stay, any related cause for epistaxis, modalities of treatment, success of balloon catheter etc.

Result: Results with double-balloon catheter showed less hospital stay and better compliance by the patient.

Conclusion: This study highlights that double-balloon catheter has a higher chance of acceptance by the patient and is better in the treatment of epistaxis. This method can be undertaken without anaesthetic assistance thus it is very feasible even in the most remote areas of our nation.
\end{abstract}

Key words: Epistaxis, Double-balloon catheter, Anterior nasal packing, Posterior nasal packing

$\mathrm{E}$ pistaxis is a common occurrence, with many of us experiencing at least one episode in a lifetime. Anterior epistaxis is more likely in children and young adults, whereas posterior epistaxis is more likely in older adults, especially men in the fifth decade of life with hypertension and arteriosclerosis ${ }^{2}$. Epistaxis is more likely in the winter months. This may be due to increased upper respiratory infections and drier air caused by the use of overheated and under humidified environment. Epistaxis is also common in hot climate with low humidity. Patients who suffer from allergy, nasal inflammation, and sinus disease are more prone to epistaxis because the mucosa is more friable and hyperemic due to inflammation.

Some of the people who contributed significantly in the management of epistaxis are:

James Lawrence Little (1879), and Wilhelm Kiesselbach who identified the arterial plexus situated on the anterior part of the cartilaginous septum as a source of epistaxis. Pilz (1868) tied the common carotid artery for the treatment of epistaxis. Alfred Seiffert (1928) first introduced the ligation of the internal maxillary artery via a transantral approach. Henry Goodyear (1937) was the first to tie the anterior ethmoid artery for epistaxis ${ }^{3}$.

\section{Materials and methods}

Patients admitted in Kathmandu Medical College, Sinamangal, Kathmandu, Nepal from Baisak 2065 to Chaitra 2066 with bleeding from the nose were taken into study. Children (below 10 years) were not included for balloon introduction because of the bigger size of the catheter. Patients with bleeding diathesis and patients with malignancy were not taken for the study. These patients were analysed on the basis of duration of hospital stay, any related cause for epistaxis, modalities of treatment, success of balloon catheter etc. Simple mathematical data-analysis were used to derive the conclusion.

Technique of application of double balloon catheter ${ }^{4}$ Antibacterial ointment was applied to the catheter. Then it was introduced in the nostril till the tip could be visualised below the uvula. First the posterior balloon was inflated with 7 to $10 \mathrm{ml}$ of sterile water little by little giving a gentle pull as we inflate. Then the catheter was withdrawn till posterior balloon seats at the choana. Now,

\section{Correspondence}

Dr. Meera Bista

Assistant Professor, Department of Otorhino-laryngology

Kathmandu Medical College, Kathmandu, Nepal

E-mail: meerabista@hotmail.com 
the anterior balloon was inflated with 15 to $30 \mathrm{ml}$ of sterile water. Balloons were left in place for 24 to 48 hours.

\section{Aftercare}

All the patients were admitted and thorough haematological investigations were done Antibiotics and antiallergics were prescribed following the procedure. Posterior pack was removed in 72 to 96 hours.

\section{Result}

In a total of 30 patients studied for 2 years, Male : female ratio was $3: 2$, showing male preponderance of the disease (Fig.2). The age of utmost frequency is at $4^{\text {th }}$ to $6^{\text {th }}$ decade of life followed by $6^{\text {th }}$ to $8^{\text {th }}$ decade (Fig. 3 ).

The most common risk factor is hypertention. In total 30 patients, 14 patients had hypertention and were on treatment. Other associated factors were Diabetes mellitus, atrial fibrillation,pulmonary tuberculosis,nasal bone fracture, chronic obstructive airway disease and septal perforation; each having one patient in these categories.Deviated nasal septum were seen in 2 patients. As compared to other simple modalities of management of epistaxis, this procedure has less failure (6.6\%). It has less hospital stay by the patient. $56.6 \%$ of the admitted patients stayed for 2-3 days only (Fig.4). This treatment has better patient compliance because it is less painful and does not need anaesthetic intervention. It also has partial airway providing better comfort to the patient. Nasty cosmetic complication like alar necrosis is not seen in this procedure.

\begin{tabular}{|c|c|c|c|c|c|}
\hline $\mathbf{S N}$ & Name & Age & Sex & Associated Factors & Duration of Stay \\
\hline 1 & Case 1 & 33 & $\mathrm{M}$ & Failure due to spicules post FESS. & 7 days \\
\hline 2 & Case 2 & 66 & $\mathrm{~F}$ & Deviated nasal septum & 3 days \\
\hline 3 & Case 3 & 50 & $\mathrm{M}$ & Hypertension & 3 days \\
\hline 4 & Case 4 & 25 & $\mathrm{M}$ & Fracture nasal bone & 10 days \\
\hline 5 & Case 5 & 95 & $\mathrm{~F}$ & & 3 days \\
\hline 6 & Case 6 & 70 & $\mathrm{~F}$ & $\begin{array}{l}\text { Chronic obstructive pulmonary disease / hypertension } \\
\text { with septal perforation }\end{array}$ & 3 days \\
\hline 7 & Case 7 & 59 & $\mathrm{~F}$ & & 2 days \\
\hline 8 & Case 8 & 65 & $\mathrm{~F}$ & Hypertension & 3 days \\
\hline 9 & Case 9 & 46 & $\mathrm{M}$ & Hypertension & 3 days \\
\hline 10 & Case 10 & 48 & $\mathrm{~F}$ & & 2 days \\
\hline 11 & Case 11 & 46 & $\mathrm{M}$ & Hyypertension & 6 days \\
\hline 12 & Case 12 & 86 & $\mathrm{~F}$ & & 2 days \\
\hline 13 & Case 13 & 64 & $\mathrm{M}$ & Hypertension and DM & 5 days \\
\hline 14 & Case 14 & 50 & $\mathrm{M}$ & Hypertension & 5 days \\
\hline 15 & Case 15 & 43 & $\mathrm{M}$ & - & 8 days \\
\hline 16 & Case 16 & 60 & $\mathrm{M}$ & - & 3 days \\
\hline 17 & Case 17 & 70 & $\mathrm{M}$ & Hypertension & 2 days \\
\hline 18 & Case 18 & 53 & $\mathrm{M}$ & Accelerated H.T.N & 4 days \\
\hline 19 & Case 19 & 66 & $\mathrm{~F}$ & Hypertension & 3 days \\
\hline 20 & Case 20 & 65 & $\mathrm{~F}$ & - & 7 days \\
\hline 21 & Case 21 & 52 & $\mathrm{M}$ & Accelerated H.T.N & 4 days \\
\hline 22 & Case 22 & 56 & $\mathrm{~F}$ & Pulmonary Tuberculosis & 5 days \\
\hline 23 & Case 23 & 90 & $\mathrm{~F}$ & Failure due to inadequate inflation of balloon & 9 days \\
\hline 24 & Case 24 & 62 & $\mathrm{M}$ & Accelerated HTN & 3 days \\
\hline 25 & Case 25 & 70 & M & - & 3 days \\
\hline 26 & Case 26 & 24 & $\mathrm{M}$ & DNS & 2 days \\
\hline 27 & Case 27 & 37 & $\mathrm{M}$ & Hypertention & 3 days \\
\hline 28 & Case 28 & 92 & $\mathrm{~F}$ & Accelerated HTN with atrial fibrillation & 7 days \\
\hline 29 & Case 29 & 35 & $\mathrm{M}$ & - & 2 days \\
\hline 30 & Case 30 & 45 & $\mathrm{M}$ & Hypertention & 4 days \\
\hline
\end{tabular}



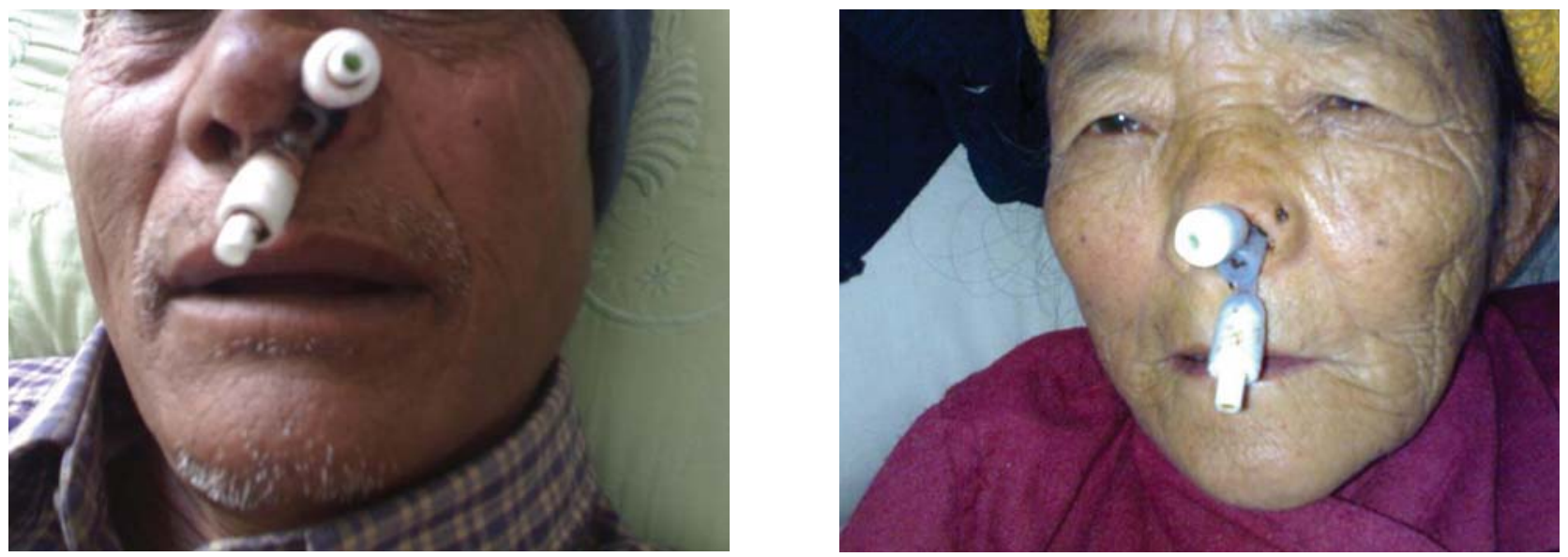

Fig 1: Patients with double balloon catheter in situ ( in KMCTH )

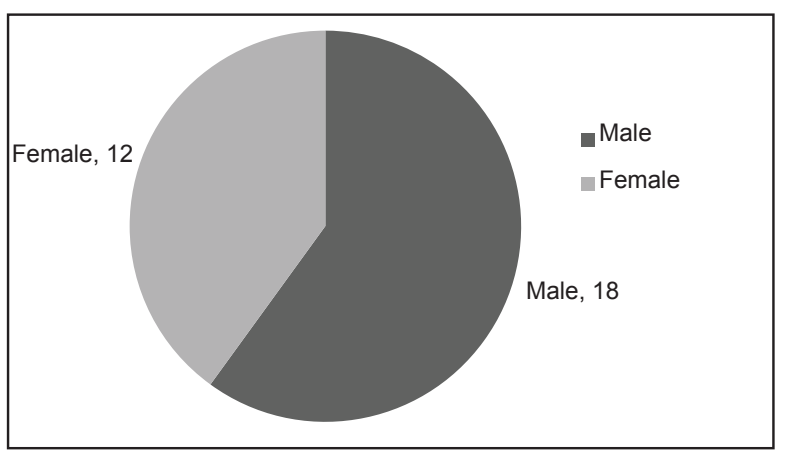

Fig 2: Male and Female Distribution

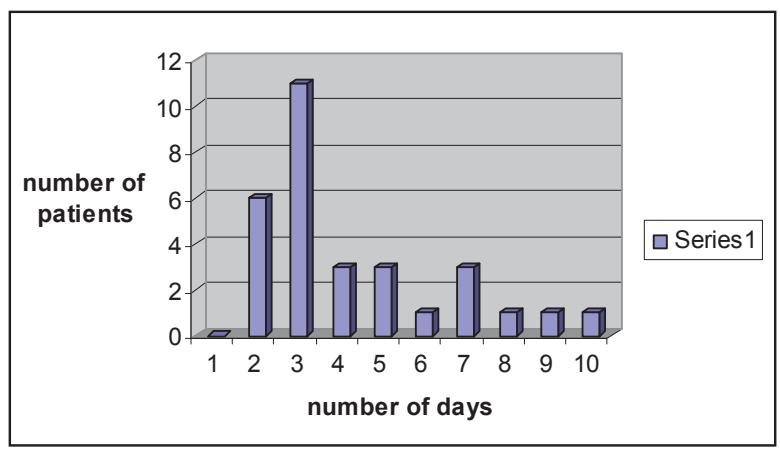

Fig 4: Days of Hospital Stay

\section{Discussion}

Double balloon catheter provides double balloon system that serves as both an anterior pack and a posterior pack. Advantages of inflatable balloon packs include: easy insertability, less traumatic to the patient, and allows a partial nasal airway.

It does not need anaesthetic assistance thus it is usable to patients with medical risk factors preventing general anaesthesia which is needed in posterior nasal packing.

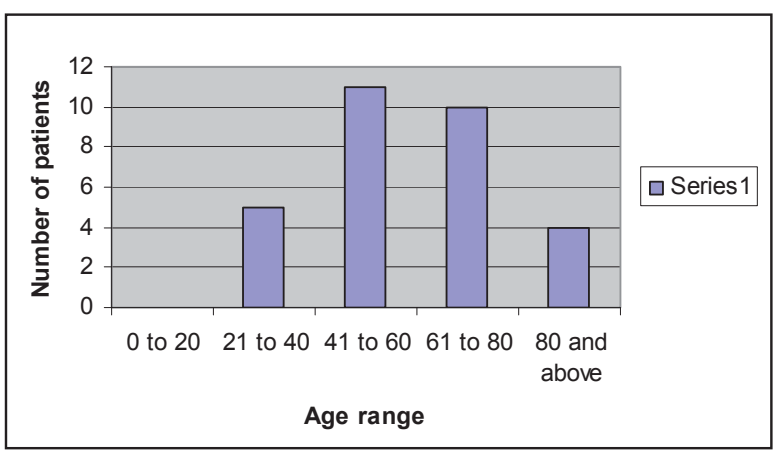

Fig 3: Age Distribution (years) of patients with epistaxis

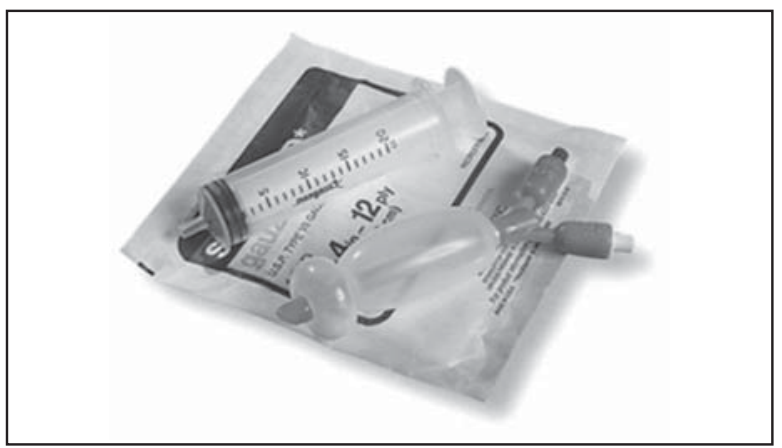

Fig 5: Double balloon catheter ${ }^{3}$

The importance of the study lies in the fact that,our country does not provide ENT services by an Otolaryngologist in most of the district hospitals. In a country, filled with immense biodiversity and minimal health facilities this method proves to be a real boon, if taught to the local Health assistants and Community Health workers. This will prevent a lot of mishaps that may occur before the patient reaches the capital where all the advance health facilities are concentrated. 
Double Balloon Epistaxis Catheter has Integral Airway designed to control intranasal bleeding. The two independently inflatable balloons assist with pressure control in the anterior and posterior chambers. The smaller balloon controls posterior bleeding while the larger balloon controls anterior bleeding. It is made from soft, medical-grade silicone. The bevelled posterior tip and soft silicone construction allows for easy placement and prevents adhesion for easy removal ${ }^{3}$.

In a total of 30 patients studied for 2 years male : female ratio is $3: 2$, showing male preponderance of the disease. P Adhikari et al in their article have shown male dominance twice as much as females in his study done in $\mathrm{TUTH}^{1}$. Male preponderance was shown by C.J.Kucik and T.Clenney also ${ }^{4}$.

The age of utmost frequency is at $4^{\text {th }}$ to $6^{\text {th }}$ decade of life. It is seen that most common age for epistaxis was more than 60 years in the study by P Adhikari et al ${ }^{1}$. Bimodal prevalence of epistaxis at 10 and 50 years was shown by C.J.Kucik and T.Clenney also ${ }^{4}$. Since in this study children less than 10 years were excluded,the first peak is most probably omitted.

The most common risk factor is hypertension in this study. Among 30 patients 14 of them (47\%) had hypertension and were on treatment. Razdan et al found hypertension as the most common systemic cause of epistaxis in his indoor patients $(62.2 \%)^{5}$. Herald et al in his work has shown that patients with epistaxis has higher blood pressure as compared to controls. In his study $79 \%$ of patients had hypertension with epistaxis. He has attributed his finding to atherosclerosis in his patients $^{2}$.

As compared to other simple modalities of management of epistaxis, this procedure has less failure thus it has less hospital stay by the patient $(6.6 \%$ only). In this study $3 \mathrm{~d}$ ays is seen to be the most common duration of hospital stay by the patient. Tabwinder Upileet al in his study has shown that approximately 2.7 days was the mean duration of patient stay in the management of epistaxis ${ }^{6}$. Likewise Daudia,A et all in his study has stated that he admitted average of 10.2 patients in 3 months with epistaxis and the average duration of stay in the hospital was 2.9 days $^{7}$.

The study shows that double balloon treatment has better patient compliance because it is less painful than posterior or anterior packing and has partial airway providing better comfort to the patient.

\section{Conclusion}

Double balloon catheter used for the management of epistaxis is an easy method which helps in management of epistaxis especially in rural areas where anaesthetic support is not available. Patients with epistaxis especially belong to elderly age group thus they have lots of comorbidities preventing them from general anaesthesia. This is an almost sure shot in the management of epistaxis as compared to other simple modalities of treatment. This causes less trauma to the nasal mucosa and does not cause nasty complications like alar necrosis. It is comfortable to the patient because of patent airway and economically smoother because of comparatively less hospital stay. In a country like Nepal were ENT service is concentrated only in the capital and nearby areas, we can conclude that double balloon catheter treatment in the management of epistaxis shows a good promise in the urban and even better promise in the rural areas of our nation.

\section{References}

1. Adhikari P, Pradhananga RB, Thapa NM, Singha BK. Aetiology and management of epistaxis at TU Teaching Hospital. Journal of Institute of Medicine.2006;28-31.

2. Herkner H, LaggnerAN, Mullner M, Formanek M, Bur A, Gamper $G$ et al. Hypertension in patients presenting with epistaxis. Annals of emergency Medicine.2000;35(2):126-30.

3. C.Hartley. The Foley Catheter in Epistaxis Management: a scientific appraisal. Journal of Laryngology and Otology.1994;108(5):399402.

4. J.kucik C, Clenney T. Management of epistaxis. American family physician. 2005;71(2):305-11.

5. Razdan U, Zara R, Chaturvedi VN. Epistaxis aetiology,site and side of bleeding. Indian Journal. 1999;53(12):545-52.

6. Upilen T, Jerjes W, Sipaul F, Maaytah M, Singh $\mathrm{S}$, Hopper C, et al. A Change in UK Epistaxis Management. Europeon Archives of OtoRhino-Laryngology. 2008;265:1349-54.

7. Daudia, A, Jaiswal V, Jones NS. Guidelines for the management of idiopathic epistaxis in adults. How we do it. Clinical Otolalyngology.33;60728. 